\title{
Las investigaciones en torno a la Real Universidad de México. Una síntesis historiográfica
}

Dante-Alberto Alcántara-Bojorge

\section{RESUMEN}

La historiografía dedicada a la Real Universidad de México ha pasado por distintas etapas desde el siglo XX, y goza de diferentes puntos de vista sobre variados aspectos de sus actividades corporativas y académicas. El artículo se encarga de proporcionar una panorámica general acerca de las principales interrogantes y problemas planteados hasta ahora, tomando como eje la historiografía impulsada por investigadores de la Universidad Nacional Autónoma de México, y plantea algunas temáticas que todavía están por explorarse.

Palabras clave: historia de la universidad, historia, papel de la universidad, México. 


\section{As pesquisas em torno à Real Universidade do México. Uma síntese historiográfica}

\section{RESUMO}

A historiografia dedicada à Real Universidade do México tem passado por diferentes etapas desde o século XX, e goza de diferentes pontos de vista sobre variados aspectos de suas atividades corporativas e acadêmicas. $\mathrm{O}$ artigo se incumbe de proporcionar uma panorâmica geral sobre as principais interrogantes e problemas expostos até agora, tomando como eixo a historiografia impulsada por pesquisadores da Universidade Nacional Autônoma do México, e propõe algumas temáticas que ainda estão por ser exploradas.

Palavras chave: história da universidade, história, papel da universidade, México.

\section{The research on the Royal University of Mexico. A historiographic synthesis}

\section{ABSTRACT}

The historiography dedicated to the Royal University of Mexico has gone through different stages since the early 20th century and presents different points of view on various aspects of its corporate and academic activities. This article provides an overview of the main questions and problems raised so far, taking as an axis the historiography promoted by researchers of the Universidad Nacional Autónoma de México, and sets out some topics that are still to be explored.

Key words: history of the university, history, role of the university, Mexico. 


\section{Introducción}

La historia de las universidades cuenta con una fértil producción historiográfica y una tradición de varios cientos de años. Lo anterior se debe en gran medida a que los interesados en ella suelen encontrar en los archivos información valiosa acerca de múltiples aspectos de su vida académica y corporativa. Así, han podido ocuparse de sus estructuras fundamentales, especialmente apoyados por la profesionalización de la disciplina de la historia desde finales del siglo XIX. En general, junto con los historiadores de la primera mitad del siglo XX, más que plantearse preguntas de investigación, buscaron dar lustre a la institución a la cual dedicaban sus desvelos. Ante la importancia que otorgaban a los documentos legales, acostumbraron abocarse a bulas, cédulas reales y estatutos universitarios. Lo anterior resultaba muy útil para conocer los marcos normativos, pero complicaba encontrar cambios y continuidades en el devenir de cada institución. Con todo, es importante reconocer que una de las contribuciones historiográficas más importantes de aquellos trabajos, fue intentar una historia comparativa de las universidades, con el fin de identificar semejanzas y diferencias entre ellas (por ejemplo, Rashdall, 1997).

Para el caso de nuestro país, la historiografía de la Real Universidad de México no es la excepción. ${ }^{1}$ Algunos de los trabajos iniciales, abrevando en la tradición historiográfica europea, en un primer momento también centraron su atención en las constituciones y estatutos de la universidad, cédulas reales, libros de gobierno, etcétera, pues resultaba la manera más rápida para conocer su complejidad y matices. ${ }^{2}$ Sin embargo, sabemos que las normas contenidas en los estatutos en la práctica se aplicaban de muy diversas maneras, pues, por ejemplo, no es lo mismo conocer un plan de estudios que preguntarse cómo se enseñaron sus contenidos, suponiendo que se hubiesen impartido. De ahí que los investigadores buscaran también otro tipo de fuentes, que dieran cuenta de la vida corporativa e intelectual de la universidad, tales como documentos relativos a su fundación, libros de matrículas, cuentas, grados, textos que se utilizaban en las aulas de las distintas facultades, entre otros. ${ }^{3}$

Así pues, en estas páginas se presenta un balance general de lo escrito en torno a la Real Universidad de México, sin pretender exhaustividad, pero dando cuenta de los temas y líneas de investigación más comunes. Se utilizan como hilo conductor las obras publicadas por investigadores pertenecientes al Instituto de Investigaciones Sobre la Universidad y la Educación (IISUE) de la Universidad Nacional Autónoma de México (UNAM), debido a que desde hace más de tres décadas allí existe un grupo de trabajo que ha promovido, en gran medida a través de la colección La Real Universidad de México. Estudios y Textos, ${ }^{4}$ el estudio de la historia de dicha universidad. Pero antes se revisará brevemente la historiografía previa, lo que permitirá conocer los antecedentes internacionales y nacionales de los estudios acerca del real estudio mexicano.

\footnotetext{
${ }^{1}$ Hoy en día contamos con varios trabajos de reflexión acerca de lo escrito en relación con la Real Universidad, su legado, nuevas interrogantes, posibles líneas de investigación, etcétera. El más reciente es el de González y Gutiérrez, 2017a. Aborda las características de algunas contribuciones: Martínez, 2013: 109-115. Enrique González expresó su juicio historiográfico en González, 2009a. Tratan la historiografía a nivel general Ramírez y Pavón, 2009; los mismos autores tocaron nuevamente el tema en Ramírez y Pavón, 2012: 179217. Enfocado en la historia de la educación conviene mencionar: González y Ramírez, 2003: 27-82. Finalmente, a las obras citadas es importante agregar estudios que iniciaron la discusión hace más de veinte años: González, 1997: 23-47; Ramírez, 1995: 269-296; Menegus y Pavón, 1987: 67-80.

${ }^{2}$ Para el caso mexicano resultan fundamentales las ordenanzas de los primeros claustros, luego los estatutos del rector Pedro Farfán (1580), los ordenados por el virrey Marqués de Cerralvo (1626) y las constituciones de Juan de Palafox y Mendoza (1644-1645).

${ }^{3}$ El archivo de la Real Universidad se conserva en el Archivo General de la Nación, su serie documental comienza en el año de su inauguración, 1553, y termina en 1863, con la supresión de la llamada Nacional y Pontificia. Una breve descripción del contenido de sus 570 volúmenes puede verse en González y Gutiérrez, 2017a: 497-500.

${ }^{4}$ En adelante, para abreviar, la llamaré Estudios y Textos.
} 


\section{Los años fundacionales de la historiografía de la Real Universidad (1930-1987)}

En un sentido diacrónico, es posible definir dos etapas dentro de la producción historiográfica mexicana. Una de ellas comenzaría hacia 1930, con la publicación de la primera guía de los fondos documentales del archivo de la antigua universidad, hecha por Nicolás Rangel (Rangel, 1930: 119-134), periodo que llegaría hasta aproximadamente 1970. El segundo momento daría inicio con la aparición de la serie Estudios y Textos, pero además estaría acompañado de otros trabajos procedentes de investigadores de distintas instituciones educativas del país.

La etapa inicial tuvo el impulso del Archivo General de la Nación (AGN) con trabajos editados en su Boletín, y también por parte de la Imprenta Universitaria; se identificó por la edición de fuentes que servirían para el estudio de la universidad. Tuvo un carácter que podría llamarse "documentalista", es decir, abocado a sacar a la luz pública papeles o textos considerados centrales para la historia. ${ }^{5}$ Con todo, tardó en germinar el proceso donde los investigadores se encargarían de plantear nuevas interrogantes, en parte porque el archivo universitario todavía no se consultaba con regularidad. Los primeros pasos se dieron a través de la serie conmemorativa Ediciones del IV Centenario de la Universidad de México, colección de 16 volúmenes que aparecieron de 1951 a 1955, y de los cuales siete (I, VIII, $\mathrm{X}, \mathrm{XI}, \mathrm{XII}, \mathrm{XIV}$ y XVI) estuvieron dedicados al real estudio mexicano. Además, fuera de la citada colección también se publicaron trabajos abocados a él. Sus autores se valieron de fuentes documentales como libros de claustros, de gobierno, de grados, de provisiones de cátedras, etcétera. Tales trabajos pusieron el énfasis en muy variados aspectos de la vida interna de la universidad, pero al entenderla principalmente como una institución de enseñanza, dejaron pendiente abordar más a profundidad el carácter de la universidad en tanto que corporación, y su relación con otros poderes y corporaciones de su tiempo. ${ }^{6}$ Es más, Enrique González asevera que si bien los trabajos se apoyaban en documentación de archivo, "jamás se discutieron problemas que no aparecieran planteados de forma inmediata por la propia fuente", predominando el tono apologético, que además disimulaba las crisis o conflictos dentro de la universidad (González, 2009a: 338). ${ }^{7}$

A partir de la década de los años setenta aparecieron otras investigaciones, no estuvieron centradas en la historia de las universidades, sino en la historia de la educación, pero enriquecieron la bibliografía hasta entonces existente. Tal fue el caso de los trabajos de Josefina Zoraida Vázquez, Anne Staples, Pilar Gonzalbo Aizpuru o Dorothy Tanck, quienes desde El Colegio de México (COLMEX) aportaron nuevos enfoques. ${ }^{8}$ Asimismo, destaca para este momento también la obra de Carmen Castañeda, investigadora abocada a la historia de la Real Universidad de Guadalajara. ${ }^{9}$

\footnotetext{
${ }^{5}$ Un ejemplo paradigmático sería la edición de la obra del secretario de la universidad: Plaza y Jaén, 1931.

${ }^{6}$ A decir de Margarita Menegus y Armando Pavón, la historiografía acerca de la universidad del periodo 1920-1970, se distinguió por: 1) Difundir las fuentes para la historia; 2) esclarecer su historia fundacional; 3) describir ceremonias, costumbres, fiestas, y 4) discutir acerca de la herencia de la tradición e influencia del modelo estatutario salmantino en la universidad mexicana (Menegus y Pavón, 1987: 67-80).

${ }^{7}$ Valiosas excepciones a este comentario, aclara el propio González, serían: Méndez, 1952, así como, Becerra, 1963. Este último fue un importante esfuerzo por entender en su conjunto la enseñanza escolarizada del virreinato.

${ }^{8} \mathrm{Al}$ menos conviene citar Zoraida, 1976; Tanck, 1977; Zoraida et al., 1981; Arce et al., 1982; Gonzalbo, 1989; 1990. Es importante añadir también que, a partir de 1978, el Seminario de Historia de la Educación del COLMEX impulsó el estudio sistemático acerca de este tema, y después de disuelto los investigadores continuaron publicando. A decir de E. González y Clara I. Ramírez, la temática de los estudios de los años ochenta "se enfocó a la educación en general, examinando temas como: conquista y educación; educación indígena; colegios, en especial los de la Compañía, aunque también los seculares; enseñanza de primeras letras, educación de las mujeres y humanismo e ilustración" (González y Ramírez, 2003: 28).

${ }^{9}$ Su obra clásica al respecto es Castañeda, 1984 [existe una segunda edición del CIESAS-Occidente, 2012], e innumerables trabajos posteriores, de historia de la educación, del libro y de la lectura.
} 
Durante los años siguientes a nivel internacional se llevaron a cabo investigaciones que apuntalaron el estudio de las universidades y con ellas aparecieron nuevas temáticas. En este sentido destacan los trabajos de Lawrence Stone (acerca de Oxford y Cambridge en los siglos XIV al XIX) y Richard Kagan (relativo a las universidades de la Corona de Castilla de 1500 a 1809), así como el libro de Mariano Peset y José Luis Peset, La universidad española (siglos XVIII y XIX), que se centró en las reformas ilustradas en las universidades españolas (Stone, 1974; Kagan, 1974 [existe edición en español, Kagan, 1981]; Peset, 1974). Enrique González indica al respecto que entre los principales aportes de Stone destacan los estudios cuantitativos sobre poblaciones escolares, así de estudiantes como de graduados y catedráticos. Agrega que lo anterior permitió averiguar el papel social de las universidades y postular que a finales de la época moderna había existido una "revolución educativa" en la mayor parte de Europa (González y Gutiérrez, 2017a: 147).

Más tarde, se publicaron otros estudios hechos en diversos países que siguieron la línea de investigación promovida por Stone y enriquecieron la visión de conjunto. Se trató de trabajos que en específico desde la historia cultural plantearon nuevas preguntas (Frijhoff y Julia, 1975; Brizzi, 1976; Chartier, Compère y Julia, 1976). ${ }^{10}$ A nivel europeo conviene mencionar que en 1960 se fundó en Estocolmo, la Commission Internationale pour l'Histoire des Universités (CIHU), que tuvo como objetivo central promover investigaciones acerca de las universidades, y con el correr de los años ha ampliado su interacción académica. ${ }^{11}$ Asimismo, en 1978 surgió en Francia la revista Histoire de l'éducation, cuyos artículos incluyen trabajos relativos a la enseñanza en las universidades y de igual forma sirvieron como acicate para la renovación historiográfica, de lo cual son buen ejemplo los trabajos de Dominique Julia. ${ }^{12}$ En el mismo sentido destaca por su repercusión en la historiografía de habla española la obra de Roger Chartier, en particular por su propuesta de atender el mundo de las "representaciones" y las prácticas culturales, centrales para el autor francés, que han fortalecido el vínculo entre la historia universitaria y otros temas, como la historia del libro y la lectura. ${ }^{13}$

Por otro lado, en 1976 se creó en la UNAM el Centro de Estudios Sobre la Universidad (CESU), el cual con el tiempo fortaleció la aparición de estudios renovadores acerca del estudio general mexicano. A través del CESU (a partir de 2006, IISUE) la historia de la universidad virreinal contó con un equipo de trabajo que se abocó a ella de una manera sistemática. ${ }^{14}$ Así, desde 1983, a los nombres de Margarita Menegus Bornemann, Lorenzo Mario Luna Díaz y Enrique González González, se sumaron otros que ampliaron los proyectos y temáticas de investigación. ${ }^{15}$ De hecho, desde 1987, año en que apareció el primer número de la colección Estudios y Textos, hasta el día de hoy, se han publicado 39 volúmenes, sin contar libros dedicados a la universidad colonial, publicados fuera de la serie. Algunos son de autoría individual, otros corresponden a obras colectivas y también incluye ediciones críticas de fuentes. En los apartados siguientes se abordará dicha colección.

\footnotetext{
${ }^{10}$ Tal vez el de mayor influencia sea el volumen de Julia, Revel y Chartier, 1986. También resulta importante el segundo tomo de Julia y Revel, 1989. En cuanto a las características de estas obras puede verse Castañeda, 2001: 17-37.

${ }^{11}$ Desde el 2005 se organizan cada año encuentros de investigadores, de los cuales se han publicado algunas actas. El resultado más reciente de los trabajos de la Comisión, con sede hoy día en Gante, puede verse en Romano, 2015.

${ }^{12}$ Véase los textos suyos citados en la nota 10.

${ }^{13}$ Numerosas contribuciones suyas gozan de traducción, lo cual facilita el acceso a ellas. Por ejemplo, de Chartier, 1982: 389-400, existe versión española: Chartier, 1992: 165-180.

${ }^{14}$ No debemos perder de vista que en la UNAM, los investigadores de otros institutos, como serían el Instituto de Investigaciones Históricas, el de Investigaciones Filosóficas, y el de Investigaciones Filológicas, también han contribuido constantemente a conocer y estudiar el pensamiento dentro de la universidad, la teología, gramática y retórica enseñadas, etcétera. Un buen ejemplo es el volumen colectivo de Irigoyen, 2003. Del mismo modo, existen trabajos desde la historia de la ciencia o la historia de la medicina, el derecho, etcétera.

${ }^{15} \mathrm{~A}$ este grupo original se agregaron después estudiantes de licenciatura que con los años llegaron a ser investigadores del Centro: Armando Pavón, Clara Inés Ramírez, Leticia Pérez, Rodolfo Aguirre, Mónica Hidalgo y Rosalina Ríos (González, 2009a: 343).
} 


\section{La historiografía desde la UNAM acerca de la Real Universidad (1987-2001)}

Según se lee en la presentación de la serie Estudios y Textos, el CESU pretendía compartir avances de investigación, tener un espacio específico dedicado a la difusión de estudios y editar documentos acerca de "la educación y la cultura novohispanas" (Luna et al., 1987: 9). De hecho, la serie mencionada inauguró su objetivo inicial de publicar fuentes documentales, en 1991. Aquel año Enrique González se encargó de imprimir y hacer un estudio introductorio del proyecto estatutario del virrey Marqués de Cerralvo. ${ }^{16}$

Ahora bien, con respecto a campos de estudio o metodologías de investigación, la historiografía que se impulsó en la colección estuvo cimentada en la historia social, de ahí que el estudio de la relación de la universidad con la sociedad fuera cobrando cada vez mayor relevancia. En este sentido, el interés en los grupos sociales dio cabida a la prosopografía (biografia colectiva) y la historia cuantitativa, que ocuparon también un lugar importante. Así, la historiografia comprometida con lo cotidiano y hecha "desde abajo" se interesó por el estudio de las poblaciones escolares, los mecanismos de ascenso social, los vínculos corporativos, etcétera. Más tarde, la historia del libro y prácticas de lectura igualmente aportó luz acerca de la circulación de saberes. En este campo de investigación las contribuciones de Chartier y su equipo de trabajo fueron significativas, pues incentivaron un acercamiento a los libros escolares y universitarios, su circulación y apropiación (Castañeda, 2001: 37).
Sin duda un contexto de fondo muy significativo para el fortalecimiento de esta historiografía fue el interés que desde 1985 tuvo en el real estudio mexicano, el historiador valenciano Mariano Peset. Su influencia y legado intelectual resulta innegable, porque "señaló por primera vez un rasgo de la universidad colonial que los estudios posteriores no harían sino confirmar: el fuerte peso de la mano real en la marcha interna de la institución" (González, 2009a: 344). Interesado en la relación de los poderes públicos con la universidad y las diferencias entre los modelos universitarios en España y el Nuevo Mundo, dirigió tesis de doctorado (por ejemplo, las de Enrique González y Armando Pavón); ${ }^{17}$ promovió trabajos de investigación con sus colegas valencianos y la organización de congresos internacionales sobre historia de las universidades hispánicas, entre otros encuentros académicos. Así, el contacto permanente entre los investigadores a nivel nacional e internacional se enriqueció, diversificándose los trabajos y fortaleciendo las aportaciones. ${ }^{18}$ Aunado a esto, el énfasis en el carácter corporativo de la universidad, coadyuvó a proponer estudios de las relaciones de sus miembros con otros órganos colegiados y poderes públicos: reyes, virreyes, arzobispos, cabildos eclesiásticos, ayuntamientos, órdenes religiosas, la real audiencia, colegios, etcétera. ${ }^{19}$

Respecto a los cortes cronológicos, indudablemente los trabajos acerca de la universidad en el siglo XVI han tenido mayor impulso, luego el siglo XVIII ha recibido también atención y, en menor medida, el

\footnotetext{
${ }^{16}$ González, 1991. Cabe añadir que la siguiente edición de alguna fuente valiosa para la historia de la educación, la hizo Mauricio Beuchot, con un estudio introductorio, compilación y notas suyas: Beuchot, 1994.

${ }^{17}$ González, 1990; Pavón, 1995. Esta última ha servido como base al autor para conformar una versión más amplia, en Pavón, 2010.

${ }^{18}$ La colaboración y empuje de Peset llevó, a partir de 1987, a la publicación de tres obras colectivas, fruto de los congresos internacionales de historia de las universidades hispánicas: Peset, 1987; Peset y Albiñana, 1989; Peset, 1998. Hasta hoy, se han organizado en México y España otros congresos con la publicación de las actas. El resultado editorial más reciente, fruto del XII Congreso internacional..., se encuentra en Hidalgo y Ríos, 2016. Acerca de este último se hablará renglones abajo, pero no debe perderse de vista que junto con Peset, también Jorge Correa Ballester ha organizado seminarios de historia de la universidad, ciencia y cultura en Europa y América, impulsando la relación académica entre investigadores de Salamanca, Valencia y México, lo cual ha coadyuvado a fortalecer la internacionalización de las investigaciones relativas al Estudio General mexicano.

${ }^{19}$ Además, los libros publicados por el IISUE de la UNAM en la colección Estudios y Textos acogieron varias tesis de grado presentadas por becarios e investigadores, que como libros contribuyeron a difundir nuevas líneas de investigación o temáticas, como se verá más adelante.
} 
siglo XVII, del cual quedan más cuestiones por despejar, en comparación con los otros. No en balde Enrique González subraya: "El "largo" siglo XVII ha sido el gran olvidado de la historiografia virreinal" (González, 2009a: 352). Si bien, en cuanto a la universidad, todavía hoy los trabajos dentro este marco histórico-temporal son menos numerosos, con todo, hay contribuciones para su estudio. ${ }^{20}$

Además, los estudios que fueron apareciendo se vincularon fuertemente con líneas de investigación de las cuales son ejemplo los trabajos que se mencionarán enseguida. En ellos los historiadores de la universidad colonial fueron presentando avances, especialmente en obras colectivas que vieron la luz durante la segunda mitad del siglo XX y principios de la siguiente centuria. Un buen ejemplo se advierte en dos libros que interesa mencionar: Tradición y reforma en la Universidad de México, seguido de Saber y poder en México (Alvarado, 1994 y Menegus, 1997). ${ }^{21}$

El primero incluye cuatro artículos destinados al Estudio General novohispano. Abre las participaciones Armando Pavón, quien dedica algunas páginas a las provisiones de cátedras de 1553 a 1564 y averigua qué tan "legales" (comillas suyas) fueron los procedimientos para ganarlas, mostrando el cuidado del claustro pleno por defender dicha legalidad. Acto seguido, Clara Inés Ramírez estudia la fundación de la cátedra de Santo Tomás (1617), exclusiva de los dominicos, e indica cómo se incorporó en la Real Universidad, contrastándola con lo sucedido en un caso semejante de la Universidad de Salamanca. Enseguida, Enrique González se pregunta si en la Universidad de México hubo inquietudes de carácter ilustrado y qué éxito tuvieron hacia 1775, año de la reedición de las constituciones universitarias, concluyendo que los enemigos del cambio lograron frenar un eventual proyecto de reforma. Por fin, Margarita Menegus revisa igualmente los conflictos entre renovadores y tradicionalistas, pero en la facultad de leyes hacia finales del siglo XVIII, e indica que la reforma de sus estudios tampoco fue aceptada.

El segundo libro mencionado, también tuvo intervención de investigadores del entonces CESU con trabajos relativos a la universidad. ${ }^{22}$ Bajo el tema de saber y poder, encontramos cuatro artículos, tres de ellos estudian la relación de los catedráticos de la universidad con los poderes externos. El primero corresponde a Clara Inés Ramírez, quien se encarga de revisar el lugar que ocupaba el saber en la promoción de los letrados en la segunda mitad del siglo XVI. Así, a través de un expediente de relación de méritos de un catedrático de artes, valora su importancia en la obtención de prebendas y beneficios, y muestra la forma como algunos personajes de la época se vinculaban con la universidad, como aval para su ascenso social. Enseguida encontramos el trabajo de Armando Pavón, quien estudia las elecciones rectorales centrándose en los conflictos entre los oidores y los clérigos en la disputa por la rectoría, de 1553 a 1574, periodo en el que estuvo en manos de estos últimos. Posteriormente Enrique González estudia la figura de Sancho Sánchez de Muñón, quien llegara a ser maestrescuela de la universidad entre 1560 y 1600. Examina su actividad como espía de Felipe II en ella, y muestra el complejo entramado político a través del cual Sánchez de Muñón influyó en el control

\footnotetext{
${ }^{20}$ Tal es el caso de Pérez, 2000. La misma autora ha estudiado otros aspectos del mismo periodo en Pérez, 1998b: 15-60; 2001: 133-161; 2005. Asimismo, es importante citar el libro de Chocano (2000), que no es fruto del trabajo colegiado de los investigadores mexicanos, pero abreva en la historia social, y estimuló la discusión en cuanto al papel de los graduados y la universidad en la defensa de sus intereses políticos frente a la Corona española.

${ }^{21}$ Ambos libros fueron resultado de un seminario interdisciplinario que se reunía por aquellos años en el CESU. Al respecto, el primer fruto del mismo se encuentra en Marsiske, 1989, donde hay un trabajo destinado a la universidad colonial, en el que Armando Pavón y Clara Inés Ramírez hacen un esbozo general del acceso de los estudiantes a las cátedras durante el siglo XVI.

${ }^{22}$ En 1996 se había publicado como parte de la colección Estudios y Textos, un libro con artículos y ponencias leídas en congresos, o incluidos en antologías. La intención fue reunir un grupo de estudios dispersos, los cuales fueron aglutinados junto a nuevos proyectos de investigación, bajo la premisa de entender el funcionamiento de la corporación colonial. Véase Ramírez y Pavón, 1996.
} 
de la corporación y obtuvo beneficios personales a cambio de servicios públicos. Finalmente, tenemos el texto de Rodolfo Aguirre, quien se pregunta cómo se proveyeron las cátedras de Leyes y Cánones (hasta 1676), y la influencia que diversos factores extrauniversitarios tuvieron en las votaciones. En concreto, el autor se refiere a cambios introducidos a partir de la creación de la Junta de Votación en dicho año, con lo cual el rey frenó el voto estudiantil. Además, revela la utilización de las cátedras para promoverse a cargos dentro de la administración virreinal o dentro de la Iglesia.

Otro buen ejemplo de los temas que se exploraron de manera sistemática lo encontramos en un volumen publicado en homenaje a Lorenzo Luna (González, 1996), en donde se incluyen cinco artículos dedicados a la universidad colonial. El primero aborda el papel de los consiliarios en el surgimiento y paulatina consolidación de la Real Universidad, entre 1553 y 1573 (Enrique González y Víctor Gutiérrez); ${ }^{23}$ otro trata la participación de dos catedráticos universitarios en la llamada conjuración de Martín Cortés, en 1566 (Armando Pavón); uno más estudia el conflicto de la Universidad con la Compañía de Jesús, a finales del siglo XVI, en cuanto al reconocimiento de cursos y grados (Clara Inés Ramírez); otro revisa la presencia de miembros de las órdenes religiosas en la universidad, y cómo lograron ocupar la rectoría entre 1648 y 1668 (Leticia Pérez); y por último, se presentan algunos avances de investigación de un estudio prosopográfico acerca de los catedráticos de la facultad de leyes, en la primera mitad del siglo XVIII (Rodolfo Aguirre).
Con los casos antes mencionados, puede advertirse que para los estudiosos de la Real Universidad el vínculo entre los saberes universitarios y los poderes públicos se trabajó a profundidad desde distintas perspectivas, en especial durante los últimos diez años de la historiografía que se viene examinando (1987-1997). Por una parte se revisaban los poderes internos de la universidad, por medio de los encargados del gobierno universitario (rectores, consiliarios, doctores, maestrescuela, etcétera); por otra, las aspiraciones y carrera académica de los catedráticos (mecanismos de promoción social y económica); por último, la relación de la corporación y sus miembros con los poderes externos (Menegus, 1997: 7-8).

Habría que agregar también una temática adicional, que desde finales de la década de 1990 fue importante para la historia del Estudio General mexicano. Se trata de investigaciones relativas a su matrícula y graduados. $\mathrm{Al}$ respecto las contribuciones de Mariano Peset y otros estudiosos españoles figuran entre los impulsos centrales, ${ }^{24} \mathrm{y}$ de allí se han realizado otros trabajos de importancia para conocer a la población universitaria. ${ }^{25}$

Finalmente, conviene mencionar que en 2001 se publicó un volumen colectivo fruto del trabajo de más de dos décadas en el CESU, bajo el título La Universidad de México. Un recorrido histórico de la época colonial al presente, y donde se presenta una síntesis histórica que incluyó un capítulo dedicado a la Real Universidad. ${ }^{26}$ Este libro significó un esfuerzo por ofrecer una visión de conjunto, fruto del trabajo de investigación realizado en los años previos, pero desafortunadamente el espacio ocupado por la universidad

\footnotetext{
${ }^{23}$ Este tema fue planteado por vez primera en el importante trabajo de Luna y Pavón, 1987: 329-350, reimpreso en Ramírez y Pavón, 1996: 22-46..

${ }^{24}$ Destacan los trabajos publicados entre 1996 y 2001: Peset et al., 1996: 171-182 [1 ${ }^{\text {a }}$ ed. en Peset, 1987: 433-443]; del mismo modo: Peset et al., 2001: 217-240 [1a. ed. Peset et al., 1999: 83-110].

${ }^{25}$ En el IISUE quienes más se han ocupado de la demografía universitaria son Armando Pavón y Rodolfo Aguirre, pues ya en su tesis de licenciatura el primero presentó un índice de grados mayores y menores de 1553 a 1601. De hecho, desde 1999 Pavón emprendió un proyecto de investigación enfocado en crear un censo de los graduados (de 1553-1738). Algunos adelantos en: Pavón 2003b: 15-49; y del mismo autor, en colaboración: Pavón et al., 2008: 119-158.

${ }^{26}$ Planteado como un texto de difusión, sin duda ha sido bien acogido por los estudiosos y público en general, muestra de ello es su segunda edición: Marsiske, 2010.
} 
virreinal quedó disminuido. De hecho, se extraña que en la colección Estudios y Textos, a más de 30 años de existencia, todavía no encontremos una historia general de la Real Universidad, de gran calado, pues si bien los trabajos monográficos favorecen una visión profunda, sería una contribución muy importante. ${ }^{27}$ Con todo, una aportación colectiva, del siglo XVI al $\mathrm{XX}$, se encuentra en la historia de la facultad de filosofía y letras, que incluye a la de artes en el periodo virreinal. $^{28}$

\section{La historiografía desde la UNAM acerca de la Real Universidad (2001-2006)}

Renglones arriba se apuntó que en 2001 fue publicada una obra de síntesis que incluía colaboraciones de los investigadores del CESU abocados a la universidad virreinal. Dicho año resulta emblemático, porque también emprendieron un proyecto que puede considerarse producto de las inquietudes intelectuales de aquel tiempo. Se trató de la exposición: "Tan lejos, tan cerca: a 450 años de la Real Universidad de México", la cual se montó en el Museo Universitario de Ciencias y Arte de la UNAM. ${ }^{29}$ Enrique González indica que en este entorno pueden situarse temas centrales que se fueron estudiando o profundizando con el paso de los años. De entrada, tendríamos los distintos proyectos de universidad que se debatieron desde su fundación, ${ }^{30}$ aspecto que iría estrechamente ligado al proceso de consolidación institucional, al que se dedicaron Armando Pavón, Clara Inés Ramírez y Rodolfo Aguirre, haciendo un seguimiento de carreras universitarias. ${ }^{31}$ Además, es preciso insistir en que el papel e influencia de los poderes externos a la corporación fue cobrando cada vez más importancia para los investigadores, asunto que no se ha agotado y hoy en día aparecen con regularidad trabajos al respecto. ${ }^{32}$ Asimismo, Leticia Pérez Puente ha estudiado la influencia del arzobispado y el cabildo de la catedral metropolitana. ${ }^{33}$

González señala también que frente a los numerosos trabajos acerca de los catedráticos, son más escasos aquellos que estudian a los profesores como autores, lo cual ayudaría a conocer mejor el papel de la universidad como productora de saberes; y tampoco se han estudiado lo suficiente los impresos de los universitarios. ${ }^{34}$ Además, añade que falta profundizar en el contenido de la docencia y los debates intelectuales de cada época, para lo cual se necesita

\footnotetext{
${ }^{27}$ Es necesario decir que Hugo Casanova coordinó hace poco un libro que aborda la historia de la UNAM de manera general, y hay participación de investigadores de la universidad colonial (véase Casanova, 2016). Allí, Enrique González atiende los distintos modelos de universidad, desde sus orígenes medievales, y sitúa a la universidad de México en el contexto de las fundadas en el Nuevo Mundo; Leticia Pérez se ocupa de las relaciones de poder entre el pontífice y la monarquía hispana, con énfasis en el papel jugado por sus representantes en la universidad mexicana; Mónica Hidalgo estudia la respuesta de esta última a las reformas borbónicas, y los cambios realizados en los colegios y seminarios novohispanos como consecuencia de aquellas. Rodolfo Aguirre atiende la transición de la universidad virreinal, y su apoyo al modelo monárquico durante el movimiento insurgente de principios del siglo XIX. Pero las temáticas de estos trabajos no tienen la finalidad de realizar una síntesis de conjunto, por lo tanto, seguimos en espera de una historia general, como se ha apuntado.

${ }^{28}$ Véase más abajo el apartado relativo a la historiografía de la UNAM, acerca de la Real Universidad (2006-2019).

${ }^{29}$ El contexto de las celebraciones organizadas por esta última (1551-2001), permitió que dicha iniciativa impactara con fuerza. Para este caso, el proyecto de contar por vez primera con un inventario de los retratos de los graduados, gozó de sus primeros resultados en el catálogo correspondiente a la exposición, donde se reprodujeron 98 de ellos (véase Ramírez et al., 2001).

${ }^{30}$ Hay una brillante síntesis en Pavón, 2001: 777-806.

${ }^{31}$ Es importante referir los libros colectivos de Pavón, 2003a, y Aguirre, 2004. Para el siglo XVII, Leticia Pérez publicó varios trabajos desde finales de la década de los años noventa. Como ejemplo se encuentran Pérez, 1998b: 15-60; 2001: 133-161. Margarita Menegus y Rodolfo Aguirre han estudiado las carreras externas de los graduados, de la primera destaca, Menegus, 1995: 83-103. Otro buen ejemplo es la obra que ella misma compiló: Menegus, 2001. Respecto a las investigaciones de Aguirre Salvador, debe mencionarse su estudio de las carreras profesionales en dos trabajos: Aguirre, 1998; también dedicado al siglo XVIII: Aguirre, 2003.

${ }^{32}$ Enrique González ha publicado varios. Sólo como ejemplo: González, 2003: 151-185; 2005: 154-192.

${ }^{33}$ Pérez, 2005.

${ }^{34}$ Como ejemplo de los primeros pasos tenemos: González, 2001: 59-73. Más recientemente: González y Gutiérrez, 2015a: 83-102, y en especial Moreno, 2018, que atiende la producción literaria impresa de los novohispanos, en las ciudades de México y Puebla, a lo largo de 120 años (1701-1821), donde los miembros de la Real Universidad, en especial doctores, ocupan un lugar destacado.
} 
estudiar la producción escrita, impresa y no (González, 2009a: 355). De hecho, en un principio los estudios al respecto venían del ámbito de la filosofía, como los hechos por Mauricio Beuchot, ${ }^{35}$ pero con el tiempo han aparecido otros desde la historia, como son los trabajos de Celina Lértora y Clara Inés Ramírez. ${ }^{36}$ Sumado a esto, se sabe todavía poco acerca de los libros académicos impresos en Europa y que circularon entre los universitarios y fuera de la universidad. ${ }^{37}$ Conviene insistir aquí en que la cultura del libro, en tanto que instrumento básico para el estudio de la circulación de saberes, es un tema que aún está por rendir sus mejores frutos, pues ayudará a entender el papel de la Real Universidad como receptora, creadora y difusora de la cultura escrita, y saberes en general.

Por otra parte, 2001 resulta igualmente emblemático porque aparecieron por vez primera dos volúmenes dedicados al estudio de los colegios y las universidades. Sin lugar a dudas los números $\mathrm{X}$ y XI de la colección Estudios y Textos, revelan que para los investigadores de la universidad colonial había quedado clara la importancia de estudiar en toda su complejidad también a los colegios novohispanos, ya fueran sólo residencias, o en algún momento de su historia también centros docentes, con lo cual comenzó a consolidarse esta línea de investigación. ${ }^{38}$ En particular en el número XI se publicaron trabajos acerca de la administración del colegio de San Pedro y San Pablo; las carreras de los colegiales de
San Ildefonso de México y del Real y Pontificio Seminario Tridentino de Puebla; la relación del colegio de Comendadores de San Ramón Nonato en la ciudad de México, con la Real Universidad; la vida cotidiana del Colegio de Niñas del Señor San Miguel (Zacatecas), entre otros.

En un principio prevaleció la relación que tuvieron los colegios novohispanos con la Real Universidad, en donde los que pertenecieron a la Compañía de Jesús o que estuvieron bajo su administración/ supervisión ocuparon un lugar importante. De lo anterior es un buen ejemplo el trabajo de Rosalina Ríos, quien estudió la transición de la enseñanza del siglo XVIII al XIX en el ex colegio jesuita de San Luis Gonzaga, y en el Instituto Literario de Zacatecas (Ríos, 2002). Así, con el tiempo se publicaron otros trabajos que han enriquecido el conocimiento de estas instituciones. ${ }^{39}$ Además, simultáneamente aparecieron estudios acerca de colegios de órdenes religiosas o del clero secular. ${ }^{40}$ De hecho, sabemos que las universidades del antiguo régimen no sólo mantuvieron relaciones estrechas con este sector, sino también con las órdenes religiosas. De ahí que los nexos entre éstas y la universidad fuera un tema que comenzó a fortalecerse también. Uno de los primeros trabajos con una visión comparativa acerca del papel de los frailes en las universidades de Salamanca y México, fue el de Clara Inés Ramírez González (Ramírez, 2001-2002). Posteriormente se han sucedido otros estudios de caso, así como trabajos

\footnotetext{
${ }^{35}$ Dentro de la serie Estudios y Textos destacan del autor: Beuchot, 1987, y su estudio, ya citado, del tratado para la enseñanza de la teología de fray Francisco Naranjo (véase la nota 16).

${ }^{36}$ El primer paso de importancia dentro de la misma colección, por su contribución a nivel colectivo a este tema, fue el de González, 2008, dicha obra incluye los trabajos de Lértora y Ramírez. La primera, además, ha dedicado un trabajo a diversos cursos teológicos y aporta un rico catálogo de obras y autores de tratados teológicos novohispanos (Lértora, 2016). Con todo, hacen falta más estudios acerca de los profesores y su enseñanza.

${ }^{37}$ En este sentido, un trabajo precursor acerca de los libros impresos en los Países Bajos, es el de González, 2009b: 183-198.

${ }^{38}$ Existe un listado para su estudio en Gutiérrez e Hidalgo, 1998: 105-114.

${ }^{39} \mathrm{El}$ estudio de los seminarios conciliares entraría dentro de esta amplia temática. Tal es el caso del trabajo de Torres, 2008.

${ }^{40}$ Un libro que no fue publicado por un investigador de la UNAM, pero su autor abreva en las propuestas metodológicas de los investigadores del área de historia de la universidad colonial, es el de León, 2001, cuyo tema es el colegio de San Nicolás de Valladolid (Morelia). Además, hay otro texto de León Alanís acerca del mismo colegio, que junto con los trabajos de Georgina Flores (respecto al colegio de San Pedro, San Pablo y San Ildefonso), y de Rosario Torres (Colegio de San Pablo de Puebla) se publicaron en Pérez y González, 2006. Por otro lado, Mónica Hidalgo (Hidalgo, 2010) ha estudiado al Colegio de San Pedro, San Pablo y San Ildefonso, en particular para el siglo XVIII.
} 
relativos a la influencia y relación del real estudio mexicano con jesuitas, dominicos, carmelitas, mercedarios, agustinos, etcétera. ${ }^{41}$

Resulta significativo subrayar que el interés académico de los investigadores del CESU en las relaciones del clero novohispano con la universidad, se conjugó con otro grupo de trabajo en el Instituto de Investigaciones Históricas (IIH) de la UNAM, donde en 2002 fue creado el "Seminario de Historia Política y Económica de la Iglesia en México". Planteado como un seminario interinstitucional, su primer producto de trabajo fue la edición en CD de los concilios provinciales mexicanos, con sus respectivos estudios y anexos (Martínez, 2004); más tarde se publicaron algunas reflexiones e investigaciones de los miembros del seminario acerca los mismos concilios, ${ }^{42} \mathrm{y}$ de hecho con el tiempo han aparecido varios libros sobre la Iglesia novohispana y en todos hay trabajos relativos a la universidad virreinal y/o acerca de universitarios. ${ }^{43}$ Aquí interesa, al menos, comentar que uno de ellos, La Iglesia en el México colonial, resulta de gran importancia por tratarse de una historia general de la institución eclesiástica con una visión renovadora y dedicada al amplio público, la cual hacía falta después de antiguas obras clásicas sobre el tema. Desde la perspectiva de una historia social de la Iglesia, los autores reflexionan acerca de cuestiones jurídicas, educación del clero, corporaciones, cofradías, parroquias, catedrales y cabildos, etcétera (Rubial, 2013). Así, el citado seminario ha ampliado la perspectiva de la historia de Iglesia, y con ella la relativa a la universidad virreinal, al pensarla - junto con los colegios - en el marco de la historia eclesiástica novohispana.

A los ejemplos anteriores habría que agregar que entre las publicaciones del IISUE dedicadas a la edición documental, encontramos el título Voces de la clerecía novohispana, volumen que reúne piezas procedentes de instituciones eclesiásticas vinculadas al arzobispado de México, cada una con su introducción al texto publicado. Presenta documentos inéditos elaborados por miembros de las órdenes religiosas, parroquias, cabildo eclesiástico, audiencia arzobispal, tribunal de capellanías, etcétera (Pérez y Aguirre, 2009). Sin lugar a dudas buena parte de su interés radica en que ensanchan el territorio de los letrados y muestran el impacto social de los universitarios en dichas corporaciones, tal como sucede con los libros publicados por el seminario interinstitucional del IIH.

Considero significativo comentar que en 2005 y 2006 se publicaron dos volúmenes de particular importancia. En ellos se muestra el resultado del VIII Congreso Internacional de Historia de las Universidades Hispánicas, que se engalanó con las celebraciones de los 450 años de la cédula de erección de la Real Universidad de México. ${ }^{44}$ Allí los estudiosos pudieron compartir experiencias y fortalecer la discusión internacional. Por lo que concierne a la universidad, en el primer volumen se aglutinan diversos trabajos, algunos relativos a la corporación y claustros de gobierno en el siglo XVI; la rectoría en distintos momentos; la hacienda universitaria en la primera mitad del siglo XVII; los destinos profesionales de los bachilleres en artes en el siglo XVIII; las provisiones de cátedras y pugnas por la rectoría del siglo XVI al siglo XVII y la promoción de graduados a cargos eclesiásticos a mediados del siglo XVIII. En el segundo fueron publicados dos artículos abocados a la universidad colonial, en específico uno acerca de la imagen que los universitarios buscaron exaltar de sí mismos, a través de sus retratos; y otro que presenta una breve reflexión con respecto a la cátedra de instituta y la enseñanza del derecho romano en la facultad de leyes.

\footnotetext{
${ }^{41}$ Un buen ejemplo se encuentra en León, 2005: 525-538; igualmente: Hidalgo, 2016: 283-306, entre otros trabajos.

${ }^{42}$ Martínez y Cervantes, 2005. Cabe añadir que al siguiente año algunos miembros del seminario publicaron: Martínez, 2006.

${ }^{43}$ Entre los libros publicados hasta ahora, el más reciente es Martínez y Cervantes, 2017.

${ }^{44}$ Se trata de los volúmenes coordinados por Leticia Pérez Puente y Enrique González González, bajo el título común de Permanencia y cambio. Véase González y Pérez, 2005; Pérez y González, 2006.
} 
Para cerrar este apartado, es necesario señalar que en la historiografia respecto a la Real Universidad, algunos investigadores se han interesado en estudiar la presencia indígena en ella. En concreto han revisado su educación y el papel del cacicazgo en la Nueva España, pues la mayoría de los graduados eran nobles pertenecientes a la élite de los naturales, y han puesto especial atención en la formación de un clero indígena. Dicho tema vino a renovar en algunos sentidos la visión que la historiografía tradicional tenía respecto a la educación de los indios, su acceso a estudios mayores y su papel social dentro de un mundo de privilegios corporativos. A ello se dedicaron, particularmente, Margarita Menegus y Rodolfo Aguirre, de lo cual son buenos ejemplos sus trabajos desde finales del siglo XX, los cuales culminaron en un volumen publicado en 2006, donde estudian la presencia indígena en el real estudio mexicano, del final del siglo XVII a la Independencia, así como su procedencia familiar (Menegus y Aguirre, 2005 y 2006). Del mismo modo, Enrique González se ha interesado en las élites indígenas, en especial por su papel dentro del proyecto intelectual del colegio de Santa Cruz de Tlatelolco (González, 2011: 91-110) y, junto con Víctor Gutiérrez, ha estudiado también el significado de su biblioteca (González y Gutiérrez, 2015b: 199-223).

\section{Historiografía desde la UNAM acerca de la Real Universidad (2006-2019)}

El 29 de septiembre de 2006 marcó un momento de cambio institucional importante para el Centro de Estudios Sobre la Universidad, pues aquel año se convirtió en el Instituto de Investigaciones Sobre la Universidad y la Educación (IISUE). Esto sin duda fortaleció el quehacer académico y el apoyo para nuevos proyectos de investigación. En dicho instituto la UNAM ha tenido un lugar privilegiado para pensarse a sí misma, lo cual también fue importante para seguir apoyando la publicación de trabajos relativos a la universidad colonial. Pero no sólo eso, pues para estos años ya era notorio que se había vuelto imperativo el estudio de otras instituciones con las que la universidad tuvo fuertes vínculos, de ahí que el examen de los colegios y sus miembros trajo consigo el de la catedral metropolitana, las parroquias, seminarios conciliares, cabildos eclesiásticos y la clerecía novohispana en general. ${ }^{45}$ Así puede verse en una obra coordinada por Rodolfo Aguirre y Lucrecia Enríquez, quienes como fruto de un simposio del 52 Congreso Internacional de Americanistas, reunieron una serie de trabajos atentos a relaciones entre la Corona y la Iglesia desde finales del siglo XVIII, los cuales pretendieron impulsar nuevas investigaciones que superaran la historia local y se abrieran a una más global e hispanoamericana (Aguirre y Enríquez, 2008). De hecho, encuentros académicos como el mencionado muestran el impacto internacional de las investigaciones en torno a la Real Universidad en otros foros, volúmenes colectivos y revistas, de lo cual han sido ejemplo las actas de los congresos internacionales de historia de las universidades hispánicas (ya citadas), celebrados alternativamente en Valencia, Salamanca y México; así como congresos de historia de las universidades en otros países como Canadá e Italia.

Acto seguido, Leticia Pérez Puente publicó un estudio acerca de las luchas de poder dentro de la clerecía novohispana, en específico sobre el papel de los religiosos en la sociedad indiana, en tiempos en que el clero secular comenzaba a consolidarse y los obispos querían normar la vida parroquial indígena (Pérez, 2010). No sobra comentar que dicha publicación se deliberó en el marco del seminario Historiografía y Fuentes Eclesiásticas Novohispanas, que coordinaba en el IISUE la misma autora. De hecho, en este

\footnotetext{
${ }^{45}$ Otro tema que por entonces comenzó a explorarse de manera sistemática fue el relativo a las finanzas. Se trabajaron documentos de ingresos y gastos universitarios en distintos periodos de tiempo pero, con todo, se trata de un aspecto todavía escasamente estudiado. Entre los estudios específicos destacan los de Tomás Ríos Hernández para el siglo XVIII (Ríos, 2006; del mismo autor en colaboración: Ríos y Sánchez, 2008: 341-363), y de Pilar Martínez López-Cano, para la primera mitad del siglo XVII (Martínez, 2005: 249-275).
} 
mismo seminario se discutió otra obra dedicada a la clerecía novohispana: Un clero en transición..., donde Rodolfo Aguirre se ocupó de trazar una visión de la relación del arzobispado de México - en particular del bajo clero - con otras instituciones eclesiásticas y políticas, en las primeras cinco décadas del siglo XVIII. Lo anterior sin dejar de lado la transición política y social de los austrias a los borbones, en las que se llevaron a cabo (Aguirre, 2012).

En los últimos años también se han editado otros volúmenes directamente relacionados con la iglesia católica en Hispanoamérica. Por principio, encontramos en la serie Estudios y Textos el libro de Leticia Pérez, Poder y privilegio..., en donde se publicaron dos textos clásicos en torno a los cabildos eclesiásticos, al tiempo que hay trabajos acerca de estos cuerpos colegiados, su papel en la política de la Corona, influencia en el real estudio mexicano, obispos, impresores, estudiantes, etcétera (Pérez y Castillo, 2016). ${ }^{46}$

Asimismo, Rodolfo Aguirre Salvador publicó como parte de la misma colección el libro Cofradias $y$ asociaciones de fieles..., el cual se encarga de estudiar un periodo de reformas eclesiásticas en el arzobispado de México, durante el cual se llevó a cabo el fortalecimiento de las cofradías y asociaciones de fieles (Aguirre, 2018). Como se ha visto, desde hace tiempo el autor se ha interesado en momentos de transición del clero novohispano, y en la obra mencionada vuelve sobre el tema, todavía escasamente trabajado. Considera que entre 1680 y 1750 el arzobispado se esforzó por conocer, reforzar y regular con rigor a las citadas hermandades, para lo cual resultaron centrales curas, jueces eclesiásticos y doctrineros. Revisa documentación relativa a los diferentes partidos del arzobispado, y concluye que los prelados pretendieron consolidar y controlar, como nunca antes, las actividades de las cofradías - especialmente en el ámbito financiero-, aunque es difícil saber qué tanto éxito tuvieron. Además, la obra arroja luz acerca del importante papel de los jueces eclesiásticos, y los párrocos, como encargados de supervisar y gobernar a las cofradías, más allá de los intereses de los arzobispos, implementado usos y costumbres que fortalecían su injerencia y estrechaban su relación con los cofrades.

En lo que toca a otras áreas temáticas, en 2008 se publicó el libro, Estudios y estudiantes de filosofía..., obra ambiciosa que tuvo como origen la conmemoración de los 450 años de la primera lección universitaria. Si bien el libro sólo se enfoca en la enseñanza y estudio de las artes, y después la filosofía, pues tuvo como objetivo hacer una historia de la Facultad de Filosofía y Letras (hasta 1929), era obligado atender aspectos históricos de la facultad de artes: sus raíces medievales, su estudiantado, graduados y catedráticos, etcétera. Así, su primera parte se refiere a la Real Universidad y en ella hay varios trabajos que se adentran en la institución, como los textos de enseñanza o las carreras profesionales de los graduados; asimismo, en la segunda parte, se estudian también a los colegios y su enseñanza de las artes (González, 2008).

Desde 1984, el CESU-IISUE cuenta con una tradición consolidada en la formación de investigadores y la discusión de avances de investigación en seminarios internos. Fruto de ese interés en la formación de futuros historiadores, el número XXIV de la colección Estudios y Textos reúne trabajos de tesistas y becarios. Cercanos a la historia social de la educación y de las universidades, sus escritos atienden la relación del real estudio mexicano, los frailes y algunos colegios novohispanos, con la sociedad de su época. Así, en la primera parte del libro hay dos trabajos acerca de las poblaciones escolares de las facultades de artes y teología, en específico en cuanto a los bachilleres

\footnotetext{
${ }^{46}$ Hay un texto reciente, que explora el devenir histórico de las actividades parroquiales en México y Yucatán. Fue publicado dentro de la colección Estudios y Textos, y coordinado por Rodolfo Aguirre Salvador: Aguirre, 2017. Lamento no haber tenido a la mano el libro para abundar acerca de su contenido y características, sin embargo, al menos es importante decir que presenta una revisión de muy larga duración, pues se exponen tanto los momentos formativos de las parroquias novohispanas, como los periodos de ajuste y cambios posteriores (al menos dentro del territorio de Yucatán y México).
} 
graduados en ellas, hechos por Adriana Álvarez y Dante Alcántara, respectivamente. Además, Gerardo Martínez presenta un artículo que estudia la repercusión de las reformas palafoxianas en la formación de los estudiantes de la facultad de medicina. Por último, Priscila Vargas atiende la presentación para grados de fray Juan de Grijava en la universidad, y Marcela Saldaña, por su parte, revisa las sustituciones de la cátedra llamada "de San Juan", en la primera mitad del siglo XVIII. En la segunda parte del volumen mencionado, encontramos estudios donde puede advertirse la relación de la universidad con cabildos y conventos, entre otros trabajos (González et al., 2009c).

Por otra parte, debe apuntarse que en 2012, los estudiosos de la universidad colonial en el IISUE rindieron un homenaje historiográfico a Mariano Peset, publicando de manera conjunta en el volumen número XXVIII de la serie Estudios y Textos, varios trabajos suyos, los cuales abordan diversas cuestiones relacionadas con la Real Universidad de México. Así, tenemos reflexiones respecto a las relaciones de la universidad de México con los poderes públicos de la época, poblaciones escolares, saberes impartidos, modelos de universidades hispánicas, etcétera. Dicho volumen muestra el impacto historiográfico de la obra de Peset y también evidencia el diálogo que el grupo de trabajo cercano a él ha tenido con los investigadores mexicanos, profundizando de manera conjunta en otros temas además de los ya mencionados (Peset, 2012). De hecho, a manera de ejemplo, Armando Pavón, en el mismo año 2012, coordinó el libro Promoción universitaria en el mundo hispánico..., donde se nota la influencia de Peset, pues en él varios investigadores se ocuparon de investigar el destino de los graduados en la burocracia eclesiástica y civil en España y América. Dicha obra es una aportación a los mecanismos de ascenso social y movilidad corporativa de los universitarios, tanto dentro de las propias universidades, como fuera de éstas, en distintas instituciones, europeas y americanas (Pavón, 2012).

En 2016 se publicó el libro Poderes y educación superior..., fruto del XII Congreso Internacional de Historia de las Universidades Hispánicas, celebrado en la Ciudad de México en 2012, para conmemorar los 25 años de la colección La Real Universidad de México. Estudios $y$ Textos. En dicho volumen encontramos trabajos englobados dentro del vasto tema de las relaciones entre los poderes y las corporaciones de enseñanza, desde el siglo XVI hasta el siglo XX. ${ }^{47}$ Se presentaron entonces dos comunicaciones acerca de los saberes jurídicos impartidos en ella a finales del siglo XVIII. Carlos Tormo Camallonga se ocupa de examinar los trámites para obtener el grado de bachiller en ambos derechos, y las gestiones hechas por los legistas foráneos. Luis René Guerrero Galván, por su parte, revisa la discusión en torno al intento de reforma al plan de estudios, llevado a cabo por el virrey Manuel Antonio Flores Maldonado Martínez de Angulo y Bodquín.

En el mismo volumen Mónica Hidalgo revisa los conflictos entre la Real Universidad y algunas corporaciones de enseñanza, ante su negativa para reconocer los cursos y grados dados en éstas, así como los mecanismos seguidos para validarlos, y Mirna Flores estudia las polémicas por la creación de la cátedra del Maestro de las Sentencias, a mediados del siglo XVIII, para los colegiales de San Ildefonso. Por último, Armando Pavón junto con Clara Inés Ramírez, y Rodolfo Aguirre por su parte, se ocupan de dos casos concretos para examinar las relaciones entre la universidad y la Iglesia. Los primeros reflexionan acerca de las acciones de los provisores de indios durante el siglo XVI y los problemas suscitados en

\footnotetext{
${ }^{47}$ Conviene subrayar que el interés de estudiar a los graduados, catedráticos, oficiales reales, miembros de la élite regional, etcétera, desde la perspectiva de grupos de poder, viene de finales del siglo XX, cuando en el aquel entonces CESU se publicaron dos libros que impulsaron dicha línea de investigación, que el citado volumen (número XXXIII de la serie Estudios y Textos) continúa. Se trata de: Menegus, 1997 y 2001.
} 
materia de jurisdicción indígena, mientras que Aguirre aborda la búsqueda de grados y capellanías por parte de algunos universitarios a mediados del siglo XVIII (Hidalgo y Ríos, 2016).

Para cerrar el presente panorama historiográfico, es preciso subrayar que los últimos números de la serie Estudios y Textos (publicados entre 2016 y 2019), han estado fuertemente vinculados a la historia de la iglesia católica romana y sus instituciones en la época moderna, a nivel hispanoamericano. Los cabildos de las catedrales novohispanas son el hilo conductor de los trabajos que aparecen en el número XXXIV, del que adelanté algo renglones arriba. Allí, a través de una colaboración colectiva, se publican textos clásicos y nuevas investigaciones, todos encaminados a examinar a aquella élite eclesiástica desde líneas de investigación que pasan por la prosopografía, la música, la religiosidad, la estética, la justicia, etcétera (Pérez y Castillo, 2016). Por otra parte, en el número XXXV se publican, con sus correspondientes estudios introductorios, los libros de siete de las nueve visitas pastorales hechas por José Lanciego Eguilaz, arzobispo de México, en la primera mitad del siglo XVIII (Aguirre, 2016).

Uno de los ejemplos más recientes del esfuerzo editorial vinculado a la edición de fuentes se encuentra en el número XXXIX de la colección Estudios y textos, que no está dedicado a documentos propios del mundo corporativo eclesiástico antes mencionado, pero sí contribuye a la historia de la universidad virreinal. En él, Enrique González se encarga de hacer una edición crítica de gran rigor académico, con notas e índices, a las constituciones mandadas a elaborar por el obispo Juan de Palafox y Mendoza, en 1645. Dicho trabajo incluye un amplio estudio introductorio de las Constituciones. Se reconstruye la historia de los diversos manuscritos y del proceso editorial llevado a cabo en los siglos XVII-XVIII. Se trata, sin duda, de un cuerpo legislativo de enorme importancia para la historia de las universidades hispánicas, y que ahora es de fácil acceso para los investigadores, con el valor añadido de que se encuentra disponible en línea (González y Gutiérrez, 2018).

Con lo dicho en las páginas anteriores se advierte que la historiografía de la universidad virreinal pasó un largo y sólido proceso de desarrollo, y ahora está en plena diversificación, pues no sólo se ha hecho más compleja en cuanto a temáticas estudiadas, sino que cada día hay más interés en otras universidades, corporaciones religiosas y centros de enseñanza del ámbito hispánico. De ahí que sea importante concluir este artículo con ejemplos recientes de la internacionalización de la labor historiográfica de los académicos del IISUE o cercanos a sus proyectos de investigación. Por principio, estarían los trabajos de Adriana Álvarez Sánchez, sobre la Universidad de San Carlos de Guatemala. Con más de diez años dedicada a la historia de las universidades, ha contribuido a conocer, desde México, diversos aspectos de aquella institución, renovando antiguas visiones en torno a sus graduados, catedráticos, la relación de la corporación con los poderes civiles y eclesiásticos, etcétera, desde el siglo XVII hasta el XIX.48 Junto con sus trabajos acerca del real estudio mexicano, ha difundido a escala internacional y desde la historia social, nuevos problemas y temas de investigación en torno a las universidades hispanoamericanas. ${ }^{49}$

De forma análoga, Gerardo Martínez Hernández ha sido partícipe de la renovación del estudio de la historia de la Medicina en México. ${ }^{50}$ Es bien sabido

\footnotetext{
${ }^{48}$ Uno de los estudios más recientes es Álvarez, 2016: 139-166. También: Álvarez, 2014.

${ }^{49}$ Por ejemplo, el tema de la movilidad de los letrados y su impacto en centros educativos de diferentes ciudades latinoamericanas: Álvarez, 2015: 81-89.

${ }^{50}$ En el IISUE, es importante destacar las contribuciones que acerca de la facultad de medicina y sus catedráticos hicieron en obras generales Armando Pavón (ver nota 17), Leticia Pérez (ver nota 20), y González, 1995: 129-144. No es lugar aquí para abundar acerca de las obras clásicas relacionadas con la medicina novohispana en general, pero es riguroso mencionar al grupo de trabajo del CEIICH en la UNAM, que han comenzado a estudiar el conocimiento y la cultura médica a nivel global, e incluyen textos relativos a la Nueva España: Pardo-Tomás y Sánchez, 2014. Y más recientemente, Morales et al., 2017.
} 
que esta línea de investigación goza de una nutrida atención desde el ámbito de la medicina, pero son pocos los autores que en la UNAM han abordado su estudio desde la historia. De ahí la importancia de la obra de Martínez, quien ha sabido encontrar vetas de investigación en ella. ${ }^{51}$ Su libro La medicina en la Nueva España, es la mejor evidencia al respecto, pues más allá del atento estudio de la Facultad de Medicina y del Real Tribunal del Protomedicato que presenta, se trata de uno de los trabajos más completos acerca de la instauración, enseñanza de la medicina y consolidación de un modelo novohispano del ejercicio médico en los siglos XVI y XVII (Martínez, 2014).

Finalmente, hay dos ejemplos recientes del impacto de la historiografía estimulada desde el IISUE en la historia de las universidades americanas, en libros editados por Leticia Pérez Puente y Enrique González González. La primera, publicó en el número XXXVI de Estudios y Textos, un cuidadoso trabajo donde revisa la aplicación de las disposiciones tridentinas haciendo un estudio comparativo de su impacto en los seminarios conciliares creados en México, Lima, Quito, Cuzco, Santa Fe, Charcas, etcétera (Pérez, 2017). Esta obra resulta fundamental, no sólo en cuanto a su importancia para la historia de instituciones de enseñanza hispanoamericanas, como seminarios, colegios y universidades, sino también por su contribución a la historia de la Iglesia en Indias, así como las relaciones de ésta con el papado y la Corona española. De hecho, la rica visión de conjunto que ofrece permite, por fin, contar con la más completa historia del impacto cultural de dicha institución en la América española, al menos en cuanto al mundo letrado del siglo XVI se refiere.

Sucede algo semejante con el libro de Enrique González González, El poder de las letras, donde se propuso el ambicioso objetivo de impulsar el estudio del pasado de las universidades americanas del periodo colonial, desde el campo de la historia social. Para ello viajó por Latinoamérica y Europa reuniendo invaluable información relativa a las principales bibliotecas y acervos documentales, no sólo universitarios, sino también de antiguas audiencias, eclesiásticos, de órdenes religiosas, regionales, municipales, del Archivo General de Indias (Sevilla), archivo de la Compañía de Jesús (Roma), etcétera. Además de conformar el más completo listado de fuentes manuscritas y material bibliográfico existente en 15 ciudades donde hubo universidad en el mencionado periodo. A la pregunta acerca de los instrumentos de consulta con los que cuenta el investigador, E. González responde con un exhaustivo panorama de repositorios accesibles, indicando de qué tipo de documentación se trata. Así, encontramos por vez primera en un mismo volumen, información pormenorizada con respecto a qué se ha estudiado de las universidades americanas y de qué modo. Sin duda, el autor hace un riguroso balance al respecto, sugiere perspectivas de investigación y dibuja un mapa detallado de la documentación útil para la historia de las universidades de la América hispana (González y Gutiérrez, 2017b).

\section{Reflexión final}

Como puede apreciarse en esta apretada relación, el esfuerzo historiográfico hecho por los investigadores dedicados a la historia de la Real Universidad de México ha sido sumamente fructífero. El conocimiento en torno a muy diversos aspectos de su vida académica y corporativa recorre una amplia franja de temas de los cuales son ejemplo numerosos artículos, ponencias, libros colectivos, obras de autor, fuentes publicadas, etcétera. A nivel metodológico, varios trabajos cultivaron la biografía colectiva y el análisis cuantitativo, se hicieron estudios comparativos y hubo una notoria influencia de la historia social. Además, esta última ha dado paso a contribuciones que integran mayores acercamientos desde la perspectiva de la historia cultural, con que se

\footnotetext{
${ }^{51}$ Por ejemplo, además de los temas dichos, su trabajo acerca del Hospital Real de Naturales, o también aspectos relacionados con el acceso de los universitarios a las cátedras: Martínez, 2016: pp. 82-96.
} 
han fortalecido algunas investigaciones de los últimos años, por ejemplo, en cuanto a los procesos de secularización, estudio de libros en tanto artefactos culturales, prácticas de lectura, etcétera. Con todo, atendiendo esta línea los estudiosos de la universidad virreinal todavía tienen el reto de profundizar en la vida estudiantil, e ir más allá de los trabajos clásicos existentes sobre el tema.

Sin duda la UNAM posee en la serie Estudios y Textos, publicada por el IISUE, un medio eficaz para la especialización en la materia, pues no existe en México una colección que tenga una cantidad semejante de títulos en tan poco tiempo: 39 números en 32 años de existencia. La colaboración constante de los estudiosos de la universidad con especialistas de otras corporaciones, dentro del marco de la historia de la Iglesia, ha enriquecido los problemas planteados en torno a la universidad virreinal, de lo cual da cuenta buena parte de la historiografía comentada. En este sentido, el trabajo colectivo entre académicos de Valencia, Salamanca y México, ha fortalecido la discusión y difusión de trabajos en diversos foros académicos. De hecho, el contacto permanente a nivel nacional e internacional hoy día rinde sus mejores frutos por medio de la internacionalización de los temas que se están estudiando actualmente acerca de colegios y universidades, lo cual tiene una fuerte presencia a nivel hispanoamericano.

Su fortaleza no es más que un aliciente para abordar nuevos aspectos y enriquecer las ópticas desde las que se emprende el estudio de la Real Universidad. Por ejemplo, si bien contamos con trabajos como el destinado a la historia de la facultad de artes, a la de filosofía, en la UNAM, es una asignatura pendiente hacer lo mismo con las facultades mayores, y aspirar a una historia de carácter general del real estudio mexicano. Se han comenzado a estudiar las bibliotecas de los universitarios, con lo que cada vez se sabe más respecto a los libros utilizados por los catedráticos, pero queda mucho por hacer. En este sentido, como se ha visto, la historiografía ha otorgado especial importancia a las relaciones de poder dentro y fuera de la corporación universitaria, y destacan aquí varios trabajos respecto a la carrera académica de los catedráticos, pero no se ha estudiado lo suficiente a estos como transmisores de saber, haciendo a un lado su papel propiamente intelectual. El mundo de los autores está por explorarse y es innegable que la gran mayoría fueron universitarios. Aun con los trabajos realizados que tocan este tema, falta profundizar en la producción intelectual de los catedráticos y la formación de los estudiantes en cada facultad, especialmente en cuanto a los teólogos y canonistas, lo cual ampliaría el panorama aquí descrito, pues permitiría conocer mejor aspectos de socialización de las ideas que van más allá de las instancias de poder. En este sentido, serán bienvenidos aquellos trabajos que se ocupen de abordar los saberes de esos universitarios, y conocer cuáles eran, cómo se recibieron y reprodujeron. Para enfrentar estos desafíos los investigadores y especialistas tendrán que redoblar esfuerzos y consolidar su manejo de la lengua latina. Hasta ahora con conocimientos suficientes de la misma han logrado solventar sus preguntas de investigación, pues la mayor parte de los libros novohispanos se escribieron en español, sin embargo, la lengua académica por excelencia en que sus autores se formaron era el latín. Además, para una lectura atenta de las tesis defendidas, cursos académicos y obras escritas (publicadas o no), el reto inmediato es dominar aquella lengua. Y sucede lo mismo con las obras académicas producidas en el Viejo mundo y que fueron leídas en México. Bajo esta línea de trabajo sin duda habrán de enriquecerse también las comparaciones con otras universidades, y podrá ubicarse mejor la producción intelectual novohispana en el concierto letrado de la época moderna a nivel global, establecer distintos momentos o etapas, y definir mejor el papel de la Real Universidad en la circulación/producción de conocimiento en el mundo hispánico, tema que sigue siendo una asignatura pendiente. 


\section{Referencias}

Álvarez Sánchez, Adriana (2016), “Los catedráticos juristas de la Real Universidad de San Carlos de Guatemala (1678-1800)", en Mónica Hidalgo Pego y Rosalina Ríos Zúniga, Poderes y educación superior en el mundo hispánico: siglos XV al XX, México, IISUE-UNAM (La Real Universidad de México. Estudios y textos, XXXIII), pp. 139-166.

Álvarez Sánchez, Adriana (2015), “Emigración letrada: graduados limeños y mexicanos en la Universidad colonial de Guatemala", Trace, núm. 68, México, CEMCA, pp. 81-99.

Álvarez Sánchez, Adriana (2014), Patronazgo y educación. Los proyectos y la fundación de la Real Universidad de San Carlos de Guatemala (1619-1687), México, FFyL-UNAM.

Aguirre Salvador, Rodolfo (2018), Cofradías y asociaciones de fieles en la mira de la Iglesia y de la Corona: arzobispado de México, 1680-1750, México, IISUE-UNAM (La Real Universidad de México. Estudios y Textos, XXXVIII). Aguirre Salvador, Rodolfo (coord.) (2017), Conformación y cambio parroquial en México y Rucatán (siglos XVI-XIX), México, IISUE-UNAM (La Real Universidad de México. Estudios y Textos, XXXVII).

Aguirre Salvador, Rodolfo (coord.) (2016), Visitas pastorales del Arzobispado de México, 1715-1722, 2 vols., México, IISUE-UNAM (La Real Universidad de México. Estudios y Textos, XXXV).

Aguirre Salvador, Rodolfo (2012), Un clero en transición: población clerical, cambio parroquial y política eclesiástica en el arzobispado de México, 1700-1749, México, IISUEUNAM/Bonilla Artigas Editores (La Real Universidad de México. Estudios y Textos, XXIX).

Aguirre Salvador, Rodolfo (2004), Carrera, linaje $y$ patronazgo. Clérigos y juristas en Nueva España, Chile y Perú (siglos XVI al XVIII), México, CESU-UNAM/Plaza y Valdés.

Aguirre Salvador, Rodolfo (2003), El mérito y la estrategia. Clérigos, juristas y médicos en Nueva España, México, CESUUNAM/Plaza y Valdés Editores.

Aguirre Salvador, Rodolfo (1998), Por el camino de las letras.
El ascenso profesional de los catedráticos juristas de la Nueva España. Siglo XVIII, México, CESU-UNAM (La Real Universidad de México. Estudios y Textos, VIII).

Aguirre, Rodolfo y Lucrecia Enríquez (coords.) (2008),

La Iglesia hispanoamericana, de la colonia a la república, México, IISUE-UNAM/Instituto de Historia-Pontificia Universidad Católica de Chile/Plaza y Valdés Editores (La Real Universidad de México. Estudios y Textos, XXI). Alvarado, Lourdes (coord.) (1994), Tradición y reforma en la Universidad de México, México, CESU-UNAM/Miguel Ángel Porrúa.

Arce Gurza, Francisco et al. (1982), Historia de las profesiones en México, México, El Colegio de México/SEP.

Becerra López, José Luis (1963), "La organización de los estudios en la Nueva España”, tesis de licenciatura, México, UNAM.

Beuchot, Mauricio (1994), El tratado de Francisco Naranjo para la enseñanza de la teología en el siglo XVII, México, CESU-UNAM/Instituto de Investigaciones Filológicas (La Real Universidad de México. Estudios y Textos, V).

Beuchot, Mauricio (1987), Filósofos dominicos novohispanos (entre sus colegios y la Universidad), México, CESU-UNAM/ Instituto de Investigaciones Filológicas (La Real Universidad de México. Estudios y Textos, II).

Brizzi, Gian Paolo (1976), La formazione della classe dirigente nel Sei-Settecento. I seminaria nobilium nell'Italia centro-settentrionale, Bologna, Società Editrice il Mulino.

Casanova Cardiel, Hugo (coord.) (2016), La UNAM y su historia. Una mirada actual, México, IISUE-UNAM.

Castañeda, Carmen (2001), "Metodología para la historia social y cultural de las universidades del Antiguo Régimen", en Enrique González González y Leticia Pérez Puente, Colegios y universidades I. Del antiguo régimen al liberalismo, México, GESU-UNAM (La Real Universidad de México. Estudios y Textos, X), pp. 17-37.

Castañeda, Carmen (1984), La educación en Guadalajara durante la colonia, 1552-1821, Guadalajara, El Colegio de Jalisco/El Colegio de México. 
Chartier, Roger (1992), "Espacio social e imaginario social: los intelectuales frustrados del siglo XVII", en El mundo como representación. Estudios sobre historia cultural, Barcelona, Gedisa, pp. 165-180.

Chartier, Roger(1982), "Espace social etimaginaire social: les intellectuels frustrés du XVIIe siècle", Annales. Économies, Sociétés, Civilisations, 37e année, núm. 2, pp. 389-400.

Chartier, R., M. M. Compère y D. Julia (1976), L'éducation en France du XVIe au XVIIIe siècle, París, SEDES-CDU.

Chocano, Magdalena (2000), La fortaleza docta. Élite y dominación social en México colonial (siglos XVI-XVIII), Barcelona, Bellaterra.

Frijhoff, Willem y Dominique Julia (1975), École et société dans la France d'Ancien Régime. Quatre exemples: Auch, Avallon, Condom et Gisors, París, EHESS.

Gonzalbo Aizpuru, Pilar (1990), Historia de la educación en la época colonial. La educación de los criollos y la vida urbana, México, El Colegio de México.

Gonzalbo Aizpuru, Pilar (1989), La educación popular de los jesuitas, México, UIA.

González González, Enrique (2011), "Los usos de la cultura escrita en el nuevo mundo, el colegio de Tlatelolco para indios principales (siglo XVI)", Estudis revista de historia moderna, vol. 37, Valencia, Universitat de València, pp. 91-110.

González, Enrique et al. (2009c), Del aula a la ciudad. Estudios sobre la universidad y la sociedad en el México virreinal, México, IISUE-UNAM (La Real Universidad de México. Estudios y Textos, XXIV).

González González, Enrique (2009b), "Libros de Flandes en la Nueva España”, en Werner Thomas y Eddy Stols, Un mundo sobre papel. Libros y grabados flamencos en el imperio hispanoportugués (siglos XVI-XVIII), Lovaina, Acco, pp. 183-198.

González González, Enrique (coord.) (2008), Estudios y estudiantes de filosofia. De la Facultad de Artes a la Facultad de Filosofia y Letras (1551-1929), México, IISUE-UNAM/ FFyL-UNAM/El Colegio de Michoacán (La Real Universidad de México. Estudios y Textos, XXII).
González González, Enrique (2005), "La corona y la tiara en las universidades coloniales de Santo Domingo, Lima y México", en Pierre Hurtubise, Université, Eglise, Culture. L'Université Catholique à l'Époque Moderne. De la Réforme à la Révolution. XVIème-XVIIIème siècles, París, Fédération Internationale des Universitiés Catholiques (FIUG), pp. 154-192.

González González, Enrique (2003), “Entre la Universidad y la Corte. La carrera del criollo Don Juan de Castilla (ca. 1560-1606)", en Armando Pavón Romero, Universitarios en la Nueva España, México, CESUUNAM (La Real Universidad de México. Estudios y Textos, XV), pp. 151-185.

González González, Enrique (2001), "Universitarios novohispanos e imprenta" en Clara Inés Ramírez, Armando Pavón y Mónica Hidalgo, Tan lejos, tan cerca: a 450 años de la Real Universidad de México, México, CESUUNAM, pp. 59-73.

González González, Enrique (1997), "Los estudios sobre historia de la universidad colonial", en Encuentro Académico XX Aniversario del CESU, México, CESUUNAM, pp. 23-47.

González González, Enrique (coord.) (1996), Historia y Universidad. Homenaje a Lorenzo Luna, México, CESUUNAM/FFyL-UNAM/Instituto de Investigaciones Dr. José María Luis Mora.

González González, Enrique (1995), "La enseñanza médica en la ciudad de México durante el siglo XVI", en José Luis Fresquet y José María López Piñero, El mestizaje cultural y la medicina novohispana del Siglo XVI, Valencia, Universitat de València, pp. 129-144.

González González, Enrique (edición crítica e introducción) (1991), Proyecto de estatutos ordenados por el virrey Cerralvo (1626), México, CESU-UNAM (La Real Universidad de México. Estudios y Textos, III).

González González, Enrique (1990), “Legislación y poderes en la universidad colonial de México (15511668)", tesis para obtener el grado de doctor en Historia, 2 vols., Valencia, Universitat de València. 
González González, Enrique et al. (2009), Del aula a la ciudad. Estudios sobre la universidad y la sociedad en el México virreinal, México, IISUE-UNAM (La Real Universidad de México. Estudios y Textos, XXIV).

González González, Enrique y Víctor Gutiérrez Rodríguez (2017a), El poder de las letras. Por una historia social de las universidades de la América hispana en el periodo colonial, México, IISUE-UNAM/BUAP/UAM/Ediciones EyC.

González, Enrique y Víctor Gutiérrez (2018), Juan de Palafox y Mendoza. Constituciones para la Real Universidad de México (1645), México, IISUE-UNAM (La Real Universidad de México. Estudios y Textos, XXXIX). González González, Enrique y Víctor Gutiérrez, Rodríguez (2015a), "Los catedráticos novohispanos y sus libros. Tres bibliotecas universitarias del siglo XVI", en Andrea Romano, Dalla lectura all'e-learning, Bologna, CLUEB, pp. 83-102.

González González, Enrique y Víctor Gutiérrez Rodríguez (2015b), "Una biblioteca de latinidad para indios caciques: Santa Cruz de Tlatelolco (México s. XVI)", en Giancarlo Angelozzi, Maria Teresa Guerrini, Giuseppe Olmi, Università e formazione dei ceti dirigenti. Per Gian Paolo Brizzi, pellegrino dei saperi, Bolonia, Bolonia University Press, pp. 199-223.

González González, Enrique y Leticia Pérez Puente (coords.) (2005), Permanencia y cambio I. Universidades hispánicas. 1551-2001, México, CESU-UNAM/Facultad de Derecho-UNAM (La Real Universidad de México. Estudios y Textos, XVII).

González González, Enrique y Clara Inés Ramírez González (2003), "Los estudios sobre historia de la educación colonial en la última década del siglo XX”, en Luz Elena Galván Lafarga, Susana Quintanilla Osorio y Clara Inés Ramírez González, Historiografia de la educación en México, México, COMIE/SEP/CESU-UNAM, pp. 27-82.

Gutiérrez, Víctor y Mónica Hidalgo Pego (1998), "Bibliografía sobre colegios novohispanos", en Leticia Pérez Puente, De maestros y discípulos. México. Siglos XVI$X I X$, México, GESU-UNAM (La Real Universidad de México. Estudios y Textos, VII), pp. 105-114.

Hidalgo Pego, Mónica (2016), "La Universidad de
México frente a los cursos y grados impartidos en otras corporaciones de enseñanza", en Mónica Hidalgo Pego y Rosalina Ríos Zúñiga, Poderes y educación superior en el mundo hispánico: siglos XV al XX, México, IISUEUNAM (La Real Universidad de México. Estudios y textos, XXXIII), pp. 283-306.

Hidalgo Pego, Mónica (2010), Reformismo borbónico y educación. El Colegio de San Ildefonso y sus colegiales (17681816), México, IISUE-UNAM (La Real Universidad de México. Estudios y Textos, XXV).

Hidalgo Pego, Mónica y Rosalina Ríos Zúñiga (coords.) (2016), Poderes y educación superior en el mundo hispánico: siglos $X V$ al XX, México, IISUE-UNAM (La Real Universidad de México. Estudios y textos, XXXIII).

Irigoyen Troconis, Martha Patricia (comp.) (2003), La universidad novohispana. Voces y enseñanzas clásicas, México, IIFL-UNAM.

Julia, Dominique y Jacques Revel (eds.) (1989), Les universités européennes du XVIe au XVIIIe siècle. Histoire sociale des populations étudiantes, Tome 2, París, EHESS.

Julia, Dominique, Jacques Revel y Roger Chartier (eds.) (1986), Les universités européennes du XVIe au XVIIIe siècle. Histoire sociale des populations étudiantes, Tome 1, Bohême, Espagne, États italiens, pays germaniques, Pologne, Provinces-Unies, París, EHESS.

Kagan, Richard L. (1981), Universidady sociedad en la España moderna (prol. de José Antonio Maravall), Madrid, Tecnos.

Kagan, Richard L. (1974), Students and Society in Early Modern Spain, Baltimore, The Johns Hopkins University Press.

León Alanís, Ricardo (2001), El colegio de San Nicolás de Valladolid. Una residencia de estudiantes, 1580-1712, Morelia, Instituto de Investigaciones Históricas-UMSNH.

León Cázares, María del Carmen (2005), "Una relación afortunada, o de cómo la existencia de la Universidad propició el establecimiento y desarrollo de la Orden la Merced en México”, en Enrique González González y Leticia Pérez Puente, Permanencia y cambio I. Universidades hispánicas. 1551-2001, México, CESU-UNAM/Facultad de Derecho-UnAM (La Real Universidad de México. Estudios y Textos, XVII), pp. 525-538. 
Lértora Mendoza, Celina A. (2016), La enseñanza novohispana de la Teología en el siglo XVIII, Buenos Aires, Ediciones FEPAI.

Luna Díaz, Lorenzo Mario et al. (1987), Historia de la Universidad Colonial (avances de investigación), México, CESU-UNAM (La Real Universidad de México. Estudios y Textos, I).

Luna Díaz, Lorenzo Mario y Armando Pavón Romero (1987), "El claustro de consiliarios de la Real Universidad de México, de 1553 al segundo rectorado de Farfán", en Mariano Peset (coord.), Universidades españolas y americanas. Época colonial, Valencia, CSICGeneralitat Valenciana, pp. 329-350.

Marsiske Schulte, Renate (coord.) (2010), La Universidad de México. Un recorrido histórico de la época colonial al presente, México, IISUE-UNAM.

Marsiske, Renate (coord.) (1989), Los estudiantes. Trabajos de historia y sociología, México, CESU-UNAM.

Martínez Hernández, Gerardo (2014), La medicina en la Nueva España, siglos XVIy XVIII. Consolidación de los modelos institucionales y académicos, México, IIH/IISUE-UNAM.

Martínez Hernández, Gerardo (2016), "Resonancias políticas en una cátedra extraordinaria en la Real Universidad de México del siglo XVIII. La lectura del Methodo medendi de Galeno", Revista Iberoamericana de Educación Superior (RIES), vol. VII, núm. 19, México, UNAM-IISUE/Universia, pp. 82-96.

Martínez López-Cano, María del Pilar (2013), "Veinticinco años de la colección La Real Universidad. Estudios y Textos", Revista Iberoamericana de Educación Superior (RIES), vol. IV, Núm. 9, México, IISUE-UNAM/ Universia, pp. 109-115.

Martínez López-Cano, María del Pilar (coord.) (2006), La universidad novohispana en el Siglo de Oro. A cuatrocientos años de El Quïjote, México, IIH/CESU-UNAM.

Martínez López-Cano, Pilar (2005), "Acercamiento a los ingresos de la Universidad de México en la primera mitad del siglo XVII”, en Enrique González González y Leticia Pérez Puente, Permanencia y cambio I. Universidades hispánicas. 1551-2001, México, CESU-UNAM/Facultad de Derecho-UnAM (La Real Universidad de México. Estudios y Textos, XVII), pp. 249-275.
Martínez López-Cano, Pilar, (coord.) (2004), Concilios provinciales mexicanos. Época colonial, versión digital en disco compacto, México, IIH-UNAM.

Martínez López-Cano, María del Pilar y Francisco Javier Cervantes Bello (coords.) (2017), Expresiones y estrategias. La Iglesia en el orden social novohispano, México, IIHUNAM/ICSYH-BUAP.

Martínez López-Cano, María del Pilar y Francisco Javier Cervantes Bello (coords.) (2005), Los concilios provinciales en Nueva España. Reflexiones e influencias, México, IIHUNAM/BUAP.

Méndez Arceo, Sergio (1952), La Realy Pontificia Universidad de México. Antecedentes, tramitación y despacho de las reales cédulas de erección, México, UNAM (Ediciones del IV Centenario de la Universidad, XII).

Menegus, Margarita (coord.) (2001), Universidad y sociedad en Hispanoamérica. Grupos de poder, siglos XVIII y XIX, México, CESU-UNAM/Plaza y Valdés Editores.

Menegus, Margarita (coord.) (1997), Saber y poder en México. Siglos XVI-XX, México, CESU-UNAM/Miguel Ángel Porrúa.

Menegus, Margarita (1995), "Graduados universitarios y carreras profesionales", en Margarita Menegus y Enrique González, Historia de las universidades modernas en América. Métodos y fuentes, México, CESU-UNAM, pp. 83-103.

Menegus Bornemann, Margarita y Rodolfo Aguirre Salvador (2006), Los indios, el sacerdocio y la Universidad en Nueva España. Siglos XVI-XVIII, México, CESU/UNAM/ Plaza y Valdés Editores.

Menegus Bornemann, Margarita y Rodolfo Aguirre Salvador (coords.) (2005), El cacicazgo en Nueva España y Filipinas, México, CESU-UNAM/Plaza y Valdés Editores.

Menegus Bornemann, Margarita y Armando Pavón Romero (1987), "La Real Universidad de México. Panorama historiográfico", en Lorenzo Mario Luna Díaz et al., Historia de la Universidad Colonial (avances de investigación), México, CESU-UNAM (La Real Universidad de México. Estudios y Textos, I), pp. 67-80. 
Morales Saravia, Angélica et al. (2017), De la circulación del conocimiento a la inducción de la ignorancia. Culturas médicas trasatlánticas, siglos XVIy XVII, México, CEIICH-UNAM/ CEFPSVLT-SEP.

Moreno Gamboa, Olivia (2018), Las letras y el oficio. Novohispanos en la imprenta. México y Puebla, siglo XVIII, México, IIFL-UNAM/Instituto de Investigaciones Dr. José María Luis Mora.

Pardo-Tomás, José y Mauricio Sánchez Menchero (eds.) (2014), Geografias médicas. Orillas y fronteras culturales de la medicina (siglos XVI y XVII), México, CEIICH-UNAM.

Pavón Romero, Armando (coord.) (2012), Promoción universitaria en el mundo hispánico. Siglos XVI a XX, México, IISUE-UNAM (La Real Universidad de México. Estudios y Textos, XXVII).

Pavón Romero, Armando (2010), El gremio docto. Organización corporativa y gobierno en la universidad de México en el siglo XVI, Valencia, Universitat de València.

Pavón Romero, Armando (coord.) (2003a), Universitarios en la Nueva España, México, GESU-UNAM (La Real Universidad de México. Estudios y Textos, XV).

Pavón Romero, Armando (2003b), "Grados y graduados en la universidad del siglo XVI", en Armando Pavón Romero, Universitarios en la Nueva España, México, GESUUNAM (La Real Universidad de México. Estudios y Textos, XV), pp. 15-49.

Pavón, Armando (2001), "La Real Universidad de México: cultura y sociedad en el siglo XVI", en José F. Román Gutiérrez et al., Felipe II y el oficio de rey. La fragua de un imperio, Madrid, INAH/Universidad de Zacatecas/Universidad de Guadalajara/Sociedad Estatal para la Conmemoración de los Centenarios de Felipe II y Carlos V, pp. 777-806.

Pavón Romero, Armando (1995), "Universitarios y universidad en México en el siglo XVI", tesis de doctorado en Historia, Valencia, Universitat de València.

Pavón Romero, Armando et al. (2008), "Las tendencias demográficas de los artistas en los siglos XVII y XVIII", en Enrique González González, Estudios y estudiantes de filosofia. De la Facultad de Artes a la Facultad de Filosofia y Letras (1551-1929), México, IISUE-UNAM/FFyL-
UNAM/El Colegio de Michoacán (La Real Universidad de México. Estudios y Textos, XXII), pp. 119-158.

Pérez Puente, Leticia (2017), Los cimientos de la iglesia en la América española: los seminarios conciliares, siglo XVI, México, IISUE-UNAM (La Real Universidad de México. Estudios y Textos, XXXVI).

Pérez Puente, Leticia (2010), El concierto imposible. Los concilios provinciales en la disputa por las parroquias indígenas, México, IISUE-UNAM (La Real Universidad de México. Estudios y Textos, XXVI).

Pérez Puente, Leticia (2005), Tiempos de crisis, tiempos de consolidación. La catedral metropolitana de la ciudad de México, 1653-1680, México, CESU-UNAM/El Colegio de Michoacán/Plaza y Valdés Editores (La Real Universidad de México. Estudios y Textos, XVI).

Pérez Puente, Leticia (2001), "Los canónigos catedráticos de la Universidad de México. Siglo XVII”, en Enrique González González y Leticia Pérez Puente, Colegios y universidades $I$. Del antiguo régimen al liberalismo, México, GESU-UNAM (La Real Universidad de México. Estudios y Textos, X), pp. 133-161.

Pérez Puente, Leticia (2000), Universidad de doctores. México. Siglo XVII, México, CESU-UNAM (La Real Universidad de México. Estudios y Textos, IX).

Pérez Puente, Leticia, (1998b), "Las cátedras de la universidad de México: entre estudiantes y doctores", en Leticia Pérez Puente (coord.), De maestros y discípulos. México. Siglos XVI-XIX, México, CESU-UNAM (La Real Universidad de México. Estudios y Textos, VII), pp. 15-60.

Pérez Puente, Leticia y Rodolfo Aguirre Salvador (coords.) (2009), Voces de la clerecía novohispana. Documentos históricos y reflexiones sobre el México colonial, México, IISUE-UNAM (La Real Universidad de México. Estudios y Textos, XXIII). Pérez Puente, Leticia y Gabino Castillo Flores (coords.) (2016), Poder y privilegio: cabildos eclesiásticos en Nueva España, siglos XVI a XIX, México, IISUE-UNAM (La Real Universidad de México. Estudios y Textos, XXXIV).

Pérez Puente, Leticia y Enrique González González (coords.) (2006), Permanencia y cambio II. Universidades hispánicas. 1551-2001, México, CESU-UNAM/Facultad 
de Derecho-UNAM (La Real Universidad de México. Estudios y Textos, XVIII).

Peset, Mariano (2012), Obra dispersa. La Universidad de México, México, IISUE-UNAM/Ediciones EyG (La Real Universidad de México. Estudios y Textos, XXVIII).

Peset, Mariano (ed.) (1998), Doctores y escolares. II Congreso Internacional de Historia de las Universidades Hispánicas (Valencia, 1995), 2 vols., Valencia, Universitat de València.

Peset, Mariano (coord.) (1987), Universidades españolas y americanas. Época colonial, Valencia, CSIC-Generalitat Valenciana.

Peset, Mariano y Salvador Albiñana (coords.) (1989), Claustros y estudiantes. Congreso internacional de historia de las universidades americanas y españolas en la Edad Moderna, 2 vols., Valencia, Universitat de València.

Peset, Mariano et al. (1996), "El recuento de los libros de matrícula de la universidad de México", en Clara Inés Ramírez y Armando Pavón, La universidad novohispana: corporación, gobierno y vida académica, México, CESUUNAM (La Real Universidad de México. Estudios y textos, VI), pp. 171-182.

Peset, Mariano et al. (1999), "La matrícula universitaria de México durante el siglo XVIII", en Cuadernos del Instituto Antonio de Nebrïa, núm. 2, Universidad Carlos III de Madrid, pp. 83-110.

Peset, Mariano et al. (2001), "Aproximación a la matrícula de México durante el siglo XVIII", en Enrique González y Leticia Pérez Puente, Colegios y universidades I. Del antiguo régimen al liberalismo, México, CESU-UNAM (La Real Universidad de México. Estudios y Textos, X), pp. 217-240.

Peset Reig, Mariano y José Luis Peset Reig (1974), La universidad española (siglos XVIII y XIX). Despotismo ilustrado y revolución liberal, Madrid, Taurus.

Plaza y Jaén, Cristóbal Bernardo de la (1931), Crónica de la Realy Pontificia Universidad de México, 2 vols., versión paleográfica, proemio, notas y apéndice de Nicolás Rangel, México, UNAM.

Ramírez González, Clara Inés (2001-2002), Grupos de poder clerical en las universidades hispánicas. Los regulares en
Salamanca y México, siglo XVI, 2 vols., México, CESUUNAM (La Real Universidad de México. Estudios y Textos, XII y XIII).

Ramírez González, Clara Inés (1995), “La Real Universidad de México en los siglos XVI y XVII. Enfoques recientes", en Margarita Menegus y Enrique González González, Historia de las universidades modernas en América. Métodos y fuentes, México, CESU-UNAM, pp. 269-296.

Ramírez, Glara Inés et al. (2001), Tan lejos, tan cerca: a 450 años de la Real Universidad de México, México, CESUUNAM.

Ramírez González, Clara Inés y Armando Pavón Romero (2012), "Historiografia sobre las universidades iberoamericanas de los siglos XVI al XVIII" en L.E. Rodríguez-San Pedro Bezares y Juan Luis Polo Rodríguez, Historiografia y líneas de investigación en Historia de las universidades: Europa mediterránea e Iberoamérica, Salamanca, Universidad de Salamanca, pp. 179-217.

Ramírez González, Clara Inés y Armando Pavón Romero (2009), "Historiografía de las universidades iberoamericanas", en L.E. Rodríguez-San Pedro y Juan Luis Polo, Historia de la Universidad de Salamanca, v. 4, Salamanca, Universidad de Salamanca, pp. 501-533.

Ramírez, Clara Inés y Armando Pavón (comps.) (1996), La universidad novohispana: corporación, gobierno y vida académica, México, CESU-UNAM (La Real Universidad de México. Estudios y Textos, VI).

Rangel, Nicolás (1930), "Ramo Universidad" [Guía], Boletín del Archivo General de la Nación, vol. 1, núm. 1, pp. 119-134.

Rashdall, Hastings (1997), The universities of Europe in the Middle Ages, 3 vols. (reeditada y anotada por F.M. Powicke y A.B. Emdem), Oxford, Oxford University Press [primera edición, 1895].

Ríos Hernández, Tomás (2006), "Esplendor y crisis en un modelo financiero en la Real Universidad de México, 1788-1821", tesis de maestría en Historia, México, FFyL-UNAM.

Ríos Hernández, Tomás y Ernest Sánchez Santiró (2008), "Las finanzas de la Facultad de artes de la Real 
Universidad de México, 1701-1810”, en Enrique González González, Estudios y estudiantes de filosofia. De la Facultad de Artes a la Facultad de Filosofia y Letras (1551-1929), México, IISUE-UNAM/FFyL-UNAM/ El Colegio de Michoacán (La Real Universidad de México. Estudios y Textos, XXII), pp. 341-363.

Ríos Zúñiga, Rosalina (2002), La educación de la colonia a la República. El Colegio de San Luis Gonzaga y el Instituto Literario de Zacateas (1754-1854), México, IISUEUNAM/UAZ/Ayuntamiento de Zacatecas (La Real Universidad de México. Estudios y Textos, XIV).

Romano, Andrea (2015), Dalla lectura all'e-learning, Bologna, CLUEB.

Rubial García, Antonio (coord.) (2013), La Iglesia en el México colonial, México, IIH-UNAM/ICSyH-BUAP/Ed. EyC.
Stone, Lawrence (ed.) (1974), The University in Society (vol. I Oxford and Cambridge from the 14th to the early 19th Century; vol. II Europe, Scotland and the United States from the 16th to the 20th Century), New Jersey, Princeton University Press.

Tanck Estrada, Dorothy (1977), La educación ilustrada. 1786 1836. Educación primaria en la Ciudad de México, México, El Colegio de México.

Torres Domínguez, Rosario (2008), Colegios y colegiales palafoxianos de Puebla en el siglo XVIII, México, IISUEUNAM/FFyL-BUAP (La Real Universidad de México. Estudios y Textos, XX).

Zoraida Vázquez, Josefina (1976), Nacionalismo y educación en México, México, El Colegio de México.

Zoraida Vázquez, Josefina et al. (1981), Ensayos sobre historia de la educación en México, México, El Colegio de México. 